\title{
Cyanotic tetralogy of Fallot in a 77 year old man
}

\author{
S.H.L. Thomas ${ }^{1}$, P. Bass ${ }^{2}$, H. Pambakian ${ }^{2}$ and J.H. Marigold ${ }^{1}$ \\ Departments of ${ }^{\prime}$ Medicine for the Elderly and ${ }^{2}$ Histopathology, St Thomas' Hospital, Lambeth Palace Road, \\ London, SE1 7EH, UK.
}

\begin{abstract}
Summary: We report the clinical details of a 77 year old man with classical tetralogy of Fallot. The patient had clubbing and cyanosis at birth, and exertional squatting in childhood. He was asymptomatic as an adult until the seventh decade, when he developed biventricular failure and had an episode of bacterial endocarditis. He finally died of cerebral infarction and bronchopneumonia following abdominal surgery.

In spite of investigations, the diagnosis was not made in life, but only discovered at post-mortem. A persistent ductus arteriosus was also found. Increased pulmonary blood flow via the ductus is believed to have facilitated this patient's unusual longevity.
\end{abstract}

\section{Introduction}

Tetralogy of Fallot is the most common form of congenital heart disease found in adults.' ${ }^{1}$ Prolonged survival is rare. Few patients live to the age of 40 years. ${ }^{2,3,4}$ We report the case of a man who survived to the age of 77 years with cyanotic tetralogy of Fallot, complicated by heart failure and bacterial endocarditis. In spite of multiple hospital admissions the diagnosis was only made at post-mortem.

\section{Case report}

A 76 year old man was referred from another hospital for assessment of a confusional state after colonic surgery. Physical examination revealed normal weight and stature, central cyanosis, atrial fibrillation, a prominent left parasternal cardiac impulse, a precordial pansystolic murmur and single second heart sound. The patient could not relate his past history, but from old records it was found that clubbing, cyanosis and a systolic murmur had been noted at birth and he had suffered exertional cyanosis and squatting as a young man. At the time his doctors had diagnosed rheumatic mitral regurgitation. Being inquisitive, the patient consulted Black's Medical Dictionary and came to the conclusion he had Fallot's tetralogy. He had remained well and led a normal life until aged 73 when he was admitted to hospital with

Correspondence: S.H.L. Thomas, B.Sc., M.R.C.P., Department of Nuclear Medicine, St Thomas' Hospital, Lambeth Palace Road, London SE1 7EH, UK.

Accepted: 3 December 1986 biventricular failure. M-mode echocardiography was reported as showing mitral valve prolapse, and consequently severe mitral regurgitation was diagnosed. The patient was treated successfully with diuretics. A further admission was required (aged 74) for treatment of Streptococcus bovis endocarditis. A barium enema was normal at this time, but two years later a rectal carcinoma was diagnosed. The confusional state developed following radical rectectomy and formation of a colostomy.

Investigations were as follows: a chest $\mathrm{X}$-ray showed cardiomegaly. Electrocardiogram showed right bundle branch block and left axis deviation. He was not polycythaemic, but the arterial $P_{2}$ was $4.86 \mathrm{kPa}$. The confusional state was attributed to a cerebral infarct demonstrated on computed tomographic scan, and did not improve over several weeks. The patient subsequently died of bronchopneumonia aged 77 years.

Autopsy revealed the classical cardiac findings of Fallot's tetralogy (Figure 1). There was infundibular pulmonary stenosis (orifice diameter $0.9 \mathrm{~cm}$ ), right ventricular hypertrophy (free wall thickness $1.5 \mathrm{~cm}$ ), a ventricular septal defect (diameter $3 \mathrm{~cm}$ ), with an overriding aorta. Other findings were a persistent ductus arteriosus, cerebral infarction, and terminal confluent bronchopneumonia.

\section{Discussion}

Prolonged survival of patients with uncorrected tetralogy of Fallot is unusual ${ }^{2,3,4}$ and often associated with a large bronchial to pulmonary collateral circula- 

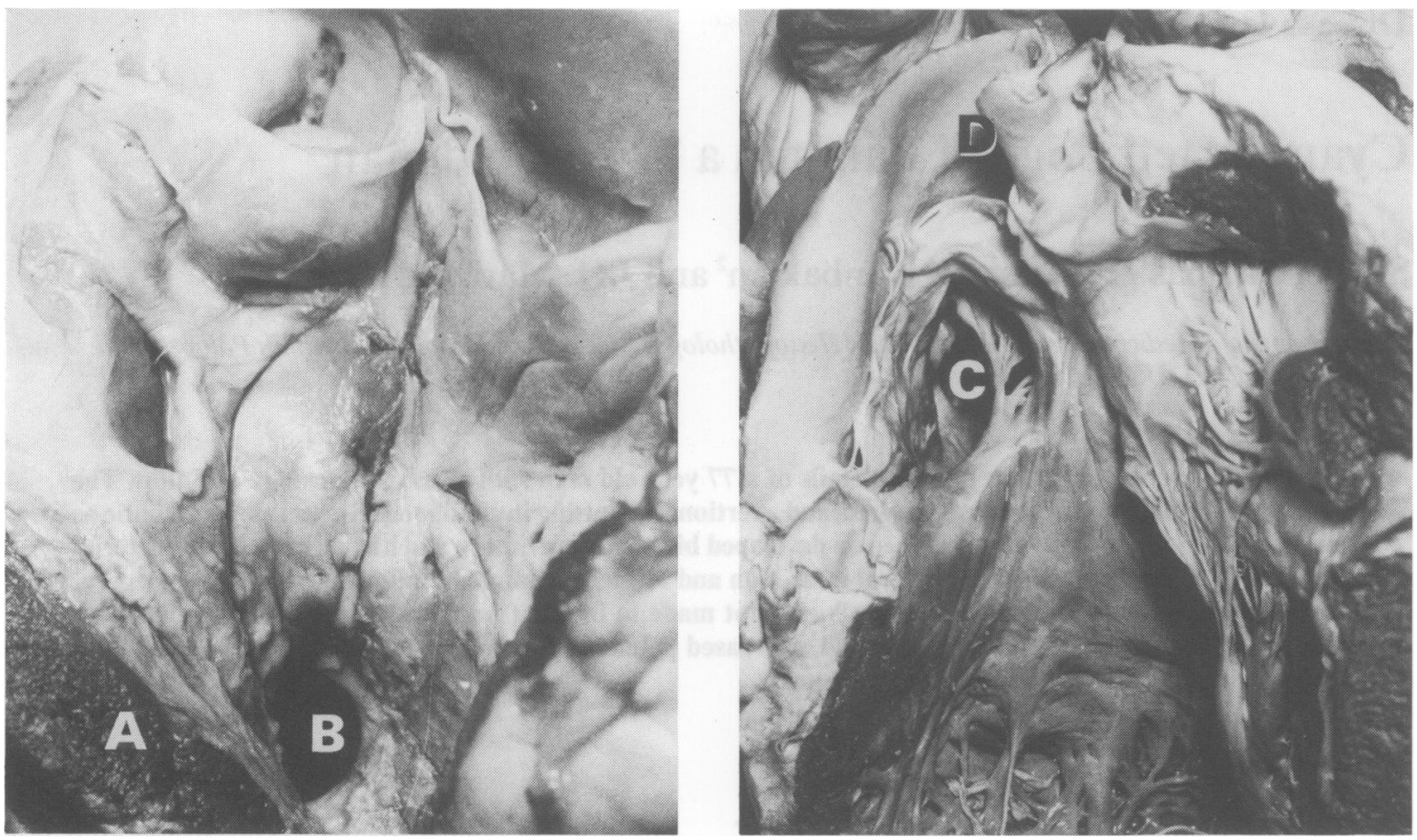

Figure 1 Cardiac findings at autopsy: A - hypertrophied right ventricle; B - infundibular pulmonary stenosis; C ventricular septal defect; D - overriding aorta.

tion and well developed left ventricle. We believe this man is the oldest reported patient with the tetralogy, and that his prolonged survival was related to increased pulmonary blood flow via the persistent ductus arteriosus. The clinical features of progressive heart failure and bacterial endocarditis have been

\section{References}

1. Wood, P. Congenital heart disease. In Disease of the Heart and Circulation, third edition, chapter VIII. Eyre and Spottiswoode, London, 1968.

2. Burch, G.E., DePasquale, N.P. \& Phillips, J.H. Tetralogy of Fallot associated with well-developed left ventricular muscle mass and increased life span. Am J Med 1964, 36: $54-61$. described before in adult tetralogy of Fallot, ${ }^{4}$ and the cerebral infarction precipitating his final illness may have been caused by paradoxical thromboembolism. Interestingly his history and symptoms were typical enough to allow the patient to diagnose his condition correctly by referring to a medical textbook.

3. Meindok, H. Longevity in tetralogy of Fallot. Thorax 1964, 19: 12.

4. Abraham, K.A., Cherian, G., Dayasagar Rao, V., Sukumar, I.P., Krishnaswami, S. \& John, S. Tetralogy of Fallot in adults. A report on 147 patients. Am J Med 1979, 66: 811-816. 